\title{
A GIS Based Laboratory in Transportation Engineering: Self-Efficacy as a Predictor of Students' Learning
}

\section{Dr. Ghulam H. Bham, University of Alaska, Anchorage}

Dr. Ghulam H. Bham is a faculty member at the Civil Engineering Department at the University of Alaska, Anchorage. He received his M.S. and Ph.D. from the University of Illinois at Urbana-Champaign. His research interests include modeling and simulation of driver behavior in transportation systems, traffic operations and control, traffic safety, and engineering education.

\section{Dr. Dan Cernusca, Missouri University of Science \& Technology}

Dr. Dan Cernusca is Instructional Design Specialist in the Department of Global Learning at the Missouri University of Science and Technology. He received his Ph.D. degree in Information Science and Learning Technologies in 2007 from University of Missouri - Columbia. He also holds a BS and a Ph.D. from the University of Sibiu in Romania with a specialization in manufacturing technologies and respectively cutting-tools design. His research interests include design-based research in technology-enabled learning contexts, technology-mediated problem solving, applications of dynamic modeling for learning of complex topics, and the impact of epistemic beliefs on learning with technology. 


\title{
A GIS Based Laboratory in Transportation Engineering: Self-Efficacy as a Predictor of Students' Learning
}

\begin{abstract}
The focus of this paper is to identify an exploratory model that links students' performance in a Geographic Information Systems (GIS) laboratory to students' perceptions and beliefs related to this experience. Self-efficacy, perceived motivation and perceived difficulty, were examined as significant predictors of students' performance outcomes. Structural equation modeling approach was adopted in this study.

The results indicate that both perceived motivation and perceived difficulty are significant predictors for students' academic self-efficacy. Higher self-efficacy produced the desired outcome as a result of better alignment of the complexity of the laboratory activity with the level of students' expectations. This outcome is of great interest as the GIS laboratory was set as a distributed learning activity implemented as stand-alone laboratories in several courses throughout the civil engineering curricula. The data used for the analyses were obtained from a four-semester study of student performance in the GIS laboratory.
\end{abstract}

\section{INTRODUCTION}

Web-enhanced instruction, ranging from basic communication support to fully immersive learning environments made promising developments in higher education lately (1). One important benefit of web-enhanced instruction is its ability to provide rich learning contexts that can help students activate cognitive processes required to solve real-life professional problems (2). These learning contexts are also more suitable to support an active and involved learner (3). These learners will develop a deeper comprehension of the ideas and concepts presented in the educational context, and will also be able to transfer the learned skills to new situations (4).

Previous research on multimedia instruction, however, showed that despite clear strengths of these learning contexts, not considering various aspects of students' perceptions engaged in multimedia instruction can reduce the effectiveness of the instructional process (e.g. 5-9). First, student-oriented factors such as usability (8) or perceived usefulness (9) have proved important for improving students' learning experiences. Second, as web-based modules became integral part of blended learning environments, their major strengths, flexibility and self-pacing, are reduced by their corresponding weaknesses. Some of these weaknesses are the lack of instructor interaction or technology-related challenges students face when using web-based tools (7).

Over the past several decades, the education and practice of engineering was certainly part of this integration of web-enhanced and active learning strategies in the learning process. 
For example in transportation engineering, the instructional context for this study, the task of educators shifted from the basic requirement of exposing students to the knowledge base for their field to that of providing students "with the tools necessary to solve new problems that arise" (10). One such tool in transportation engineering is Geographic Information Systems (GIS). The use of GIS was identified as one of the top skills required for civil engineers. However, courses in transportation engineering currently offered at US universities are behind in offering the needed support for students to learn GIS-related skills (11). This clearly presents the need for inclusion of GIS in civil engineering curriculum and more specifically for transportation professionals.

The major goal of the study is to identify and test an exploratory model that links students' performance to their perception and beliefs based on a multi-semester implementation of a GIS transportation laboratory.

\section{IMPLEMENTATION OF A GIS-BASED LABORATORY FOR CIVIL ENGINEERS}

At Missouri University of Science and Technology (MS\&T), civil engineers are exposed to Geographic Information Systems (GIS) through a series of stand-alone laboratories built around a distributed learning model customized for specific areas: environmental, geotechnical, surveying, transportation and water resources $(12,13)$. The major goal of this learning model was to help students build GIS-related skills by contextualizing the software application in various civil engineering fields. That is, learning outcomes changed from mere understanding of GIS mechanics to building higher-level cognitive skills needed to make this tool useful for various civil engineering applications. Learning of this tool became then a cumulative result of its use in individual courses part of civil engineering curricula. The online tutorial, the core instructional tool for these GIS-based laboratories, provides a high level of detail and richness of content such as built-in videos that can play while users are engaged in the learning exercises (14). An example of the GIS environment is presented in Figure 1.

\section{Implementation of the GIS-Based Laboratory in Transportation Engineering}

The main goal of the transportation module of the GIS laboratory was to introduce traffic safety using the ArcGIS software. An iterative process using several implementation cycles helped the instructor to refine the structure of instructional tasks based on student-centered feedback as described in the following subsections. The iterative refining process covered four semesters, Fall 2009, Spring 2010, Fall 2010 and Spring 2011.

\section{$\underline{\text { Nature of Instructional Activities }}$}

The nature of instructional activity in the GIS laboratory changed throughout the four implementation cycles. During first two semesters the GIS laboratory was a stand-alone instructional activity placed at the beginning of the course with minimal classroom support from the teaching assistants. The assumption was that students will fully use the GIS online tutorial to pace their learning process. To test the validity of this assumption, the researchers used a quasiexperiment that included a treatment group of students exposed to an instructor-led short introduction. 
This introduction focused on explaining both the role of the GIS data analysis in transportation engineering and the specific goals of this GIS laboratory. Findings from this first implementation showed clearly that the focused introduction on GIS applications in transportation helped students' learning (15).

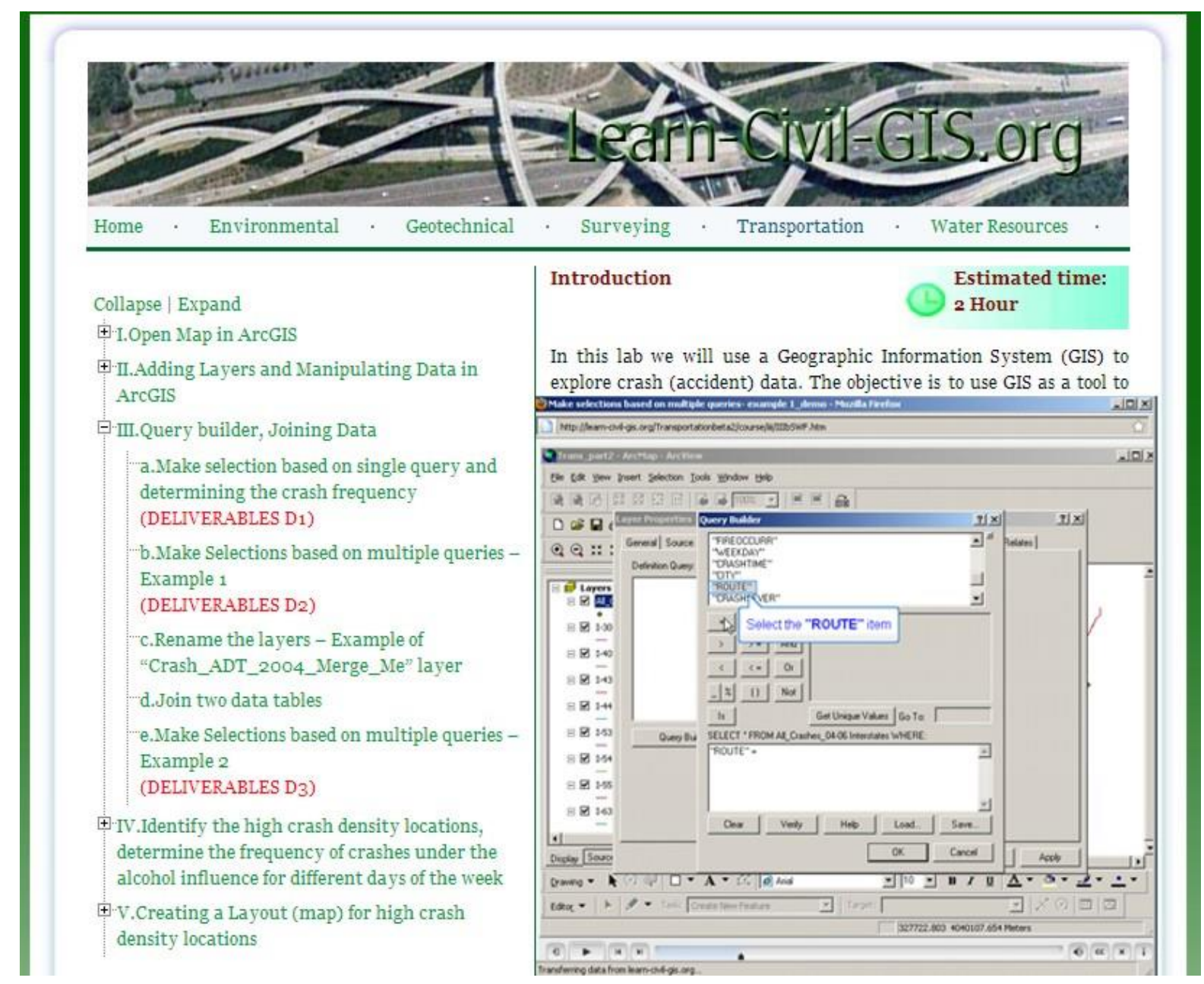

Figure 1. Example web-based screen showing the embedded video for query building.

Therefore, the instructor decided to move the GIS laboratory toward the end of the semester by linking it to the highway design project, the major hands-on activity in the course. This new structure of the instructional activities was implemented during the last two semesters of the period analyzed in this study (Fall 2010 and Spring 2011).

\section{$\underline{\text { Structure and Complexity of Instructional Tasks }}$}

The structure and complexity of the instructional tasks changed over the implementation cycles. Four major task structure factors that defined the complexity of the instructional tasks throughout this study are presented in the following part of this section. 
Students' Familiarity with the Topic and the Context of GIS Laboratory. The basic design of the online tutorial used in the GIS-based laboratory focused on supporting a self-guided and selfpaced learning process using a progressive scaffolding approach (13). However, when the basic design was implemented, students were not able to fully benefit from this progressive scaffolding approach. That is, during the first two semesters when this design was implemented, the GISbased laboratory was administered very early in the course when students were not familiar with traffic safety issues, the major focus of this laboratory. To address this issue, starting with the second semester (Spring 2010) the laboratory started with a more detailed introduction that covered traffic safety topics as well as the role of GIS software in analyzing safety information.

Finally, to significantly increase students' familiarity with the topic, for the last two semesters of this study, Fall 2010 and respectively Spring 2011, the GIS-based laboratory was anchored (16, 17 ) in the context of a major activity of the course, the semester-long highway design project. As the laboratory moved toward the end of the semester, students had the opportunity to get familiar with various aspects of traffic safety both from the lecture and from the highway design project. Therefore, the mini-lecture on traffic safety issues developed in the previous semesters served as a reinforcement of the importance of this topic for transportation engineers rather than to merely increase awareness.

GIS Dataset Size and Diversity. The initial implementation of the GIS-based laboratory (Fall 2009) in the transportation engineering course used a complex dataset with about 21,000 records of highway crashes that covered an entire state and various types of roads. The sheer size of this database posed significant challenges for students to download and save on the local computer, which often created delays in the flow of the laboratory activity. These delays generated student frustrations and lowered the effectiveness of the instructional process. In addition, students that were not able to complete the entire task during the three hours allocated for GIS laboratory, had to deal with these frustrations again since the database files saved on the laboratory computers were automatically discharged at the end of the day.

During the second implementation of the laboratory covered in this study, Spring 2010, the dataset size was reduced to about 5,900 crashes and covered only major highways within a given state. In addition, the length of the laboratory changed from three to two hours, due to a general departmental decision to address the increased need for laboratory space across campus. This requirement placed a more specific constraint on the number of tasks students could perform in the laboratory. The major focus was on changing the instructional flow to reduce the activity time while keeping the major goals of the GIS-based laboratory. The initial instructional flow involved a two-step sequence where students had to conduct a set of tasks in the online tutorial and then repeat them for a similar set of tasks (near-transfer tasks). The new instructional flow required students to perform these tasks only once, and use specific online tutorial modules as worked examples to complement the information needed to complete these tasks.

Finally, during the last two implementations that are the focus of this paper, the database size was reduced to about 250 crashes that covered a specific segment of a highway. This change reflected the shift in the context of the GIS-based laboratory that moved from being a standalone laboratory activity in the beginning of the semester to becoming a final part of a semesterlong highway design project. 
To support the authenticity of this laboratory's tasks, the traffic safety dataset was therefore limited to the segment of the highway that was the students' focus in a highway redesign project throughout most of the semester. However, it has to be mentioned that the reduction of the dataset size did not significantly changed the diversity of the traffic safety data to be analyzed. Therefore, the instructional tasks to be completed were similar in number and complexity with the ones implemented in the second semester, as described above.

Clarity and Extensiveness of Instructional Materials. For the first semester of this study (Fall 2009), the laboratory materials were scattered across several mediums. The instructional materials related to initial tasks driven by the online tutorial resided online, while the materials related to the transfer tasks resided in Blackboard, the course content management system. However, these materials did not include any formal information related to traffic safety issues. During the second stage (Spring 2010), the laboratory materials included traffic safety issues along with a short introduction on the importance of GIS software for this topic and the main deliverables for the final report.

Finally, for the last two stages of this study, Fall 2010 and Spring 2011, when the GIS-based laboratory followed the highway design project, the laboratory materials included some additional information that previously had proved to be challenging for students. One such addition was a short introduction to queries including their definition, structure and syntax. This introduction proved to be a good help for this diverse group of students, with many lacking basic programming skills associated with database use.

Nature of Face-to-Face Support. Following the patterns described, the face-to-face support offered by the instructor and the graduate teaching assistants evolved during the four semester of implementation. It started as a very limited technical assistance and evolved into a formal instructional support activity. That is, the face-to-face support during the last two semesters included mini-lectures designed to introduce various laboratory topics and their major tasks. However, besides the face-to-face support, students had to rely throughout all four phases of this study on the online tutorial for the conceptual support and scaffolding needed for each specific task.

\section{STUDENT PERFORMANCE IN THE GIS LABORATORY}

\section{Assessment Constraints}

In traditional course settings, an instructor uses a series of assessment tools and strategies to evaluate student performance. However, from an assessment perspective, the proposed GIS laboratory for transportation engineers has three major characteristics that differentiate it from the traditional course activities. First, the GIS-based laboratory is a two-hour instructional task, relatively short compared to more traditional topic-driven instructional activities in a course and therefore assessment can be only tied to lower level of cognitive processes (remember, understand). Second, this laboratory takes place only once during the course and therefore the instructor does not have the option of using formative assessment strategies. Finally, this GIS laboratory is part of a networked set of instructional activities part of the civil engineering curriculum. 
The assessment then should also be able to predict this GIS laboratory's potential impact on students' long-term performance in future similar GIS-based laboratories and related activities.

Considering the above-discussed three characteristics, this GIS- laboratory in transportation was, from an assessment perspective, closer to a training workshop than to a regular course-based activity in higher education. It was then appropriate to use training-related assessment strategies to evaluate the outcomes of this activity. Self-efficacy, in this regard, has proved to offer both a proxy for trainees' behavior, work performance, and an important training outcome in itself (18, 19). Davis and colleagues (20) indicated that self-efficacy also has a strong relationship with significant predictors of deep learning such as structural knowledge (21).

\section{Self-Efficacy as Predictor for Performance}

Self-efficacy has been defined as an important step toward a unifying theory of behavioral change (19). It determines the level of effort learners will extend in future activities and the degree to which this effort will be sustained when learners will face obstacles and challenging experiences such as associated with e-Learning (22). That is, learners with high self-efficacy will participate in a given task more readily, will work harder, and persist longer when they encounter difficulties.

In educational settings, self-efficacy has also proved to be a good predictor of students' learning and motivation in subsequent tasks $(22,23)$. The information used to appraise self-efficacy resides in past and current performance, and the feedback associated with these performances. In addition, students' success has proved to increase self-efficacy while failure has proved to decrease it (23). According to Stajkovic and Luthans (18), self-efficacy has a positive and strong relationship to work performance.

Self-efficacy, however, does not compensate for lack of prior knowledge and skills and therefore it will not produce high performance scores when these factors are lacking. This is especially true when positive feedback (e.g. “... you can do this!”) is used to increase students' self-efficacy and, consequently, to determine their increased engagement in a given task. If the student lacks prior knowledge and skills needed to complete a task, this increase in self-efficacy will be temporary when subsequent efforts turn out unsuccessful (23). Self-efficacy was also found to have a complex mediating relationship with the learning antecedents and learning outcomes (24). However, when the focus was on using online learning and tutoring modules, the results in the research literature are mixed. For example, in an engineering course where e-learning modules were used, self-efficacy showed a significant low to medium positive correlation with students' learning but was not a significant predictor of post-test scores (25). In another study, where students used web-based worked examples, self-efficacy did not mediate between the use of web-based modules and achievement as predicted. It rather served as a complementary measure of learning performance predicted by the students' use of web-based worked examples (26).

Theoretical and empirical analyses of major determinants of self-efficacy in both educational and work environments found both internal and external determinants of self-efficacy. Of these, motivation and task complexity have proved to be both significant and low variability determinants of self-efficacy $(18,27)$. 
Students' motivation in relation to the performed instructional task proved to have a positive relationship with self-efficacy, while task complexity proved to have a negative relationship to self-efficacy. If motivation is mainly an internal factor influenced by students' perception of the overall instructional environment, task complexity has both an external and an internal characteristic. Along with clear external factors such as complexity of instructional components, dynamic aspects and level of informational cues (28), task complexity also has an internal aspect due to students' perception of the components. This perception results from the interaction between the external factors of task complexity and students' experiences with same, or similar, type of tasks $(18,29)$.

Considering the changes in the nature and complexity of the instructional activity in the GIS laboratory as well as the nature and constraints of the associated assessment process, a predictive model that would identify the main factors (predictors) of student success in the GIS laboratory was desired. One potential outcome of this paper is to produce a predictive model that could serve as a starting point for monitoring the success of implementation for similar instructional activities.

\section{RESEARCH GOALS}

Considering the fact that the instructional process in the GIS laboratory was similar to that of a short-term training, the authors were first interested if overall self-efficacy and its determinants, perceived motivation and perceived task difficulty, were significant predictors for students' performance outcomes. Second, the authors were interested in finding if the major change in the instructional process, the association of the GIS laboratory topic with the major task in the course, the highway design project, produced significant change in students' self-efficacy.

\section{MODELLLING STUDENT PERTORMANCE IN THE GIS LABORATORY}

Based on the results from the analysis of factors that influence students' performance, researchers propose a path analysis model that builds on the predictive power of academic selfefficacy and two of its determinants, perceived motivation and perceived task difficulty, on students' performance outcomes.

\section{Path Model Variables}

Data associated with path variables were collected throughout the four semesters using an unannounced exit survey administered online in the lab in the week following the GIS laboratory.

\section{$\underline{\text { Student Performance }}$}

Five multiple-choice and fill-in-the-blank assessment items tested their recall of traffic safety issues covered in the GIS laboratory. Students had no prior preparation associated with this test. Of these five assessment items, two were common for all semesters and three were equivalent in difficulty, but different for the stand-alone (first two semesters) and context-driven approach (last two semesters). This adjustment reflected the nature of the analyses required by the crash datasets used for the two slightly different laboratory strategies. 
Raw assessment score were computed as a percentage of sums of correct answers ( 0 for wrong answer and 1 for correct answer) to total possible points. The average score for the four semesters was $65.44 \%$ and ranged between a minimum of $20 \%$ and the maximum possible of $100 \%$. Since students had no opportunity to prepare for the test, the test performance scores were compared to the retention rates as measured in memory retention experiments, rather than to the traditional pass or fail percentages used in higher education assessment. The mean percentage scores for retention rates after one week vary from $46 \%$ for more complex items, such as fill-inthe blanks, to $75 \%$ for simple items such as multiple-choices $(29,30)$. Therefore the mean score for the GIS laboratory was situated within the acceptable ranges of retention.

\section{$\underline{\text { Self-Efficacy }}$}

A self-efficacy scale validated in the educational literature was used for this study (32). The scale has nine self-efficacy statements and uses a five-point Likert evaluation scale (1-Totally Disagree to 5-Totally Agree). The internal reliability for the self-efficacy scale was strong. For the four-semester dataset, Cronbach's alpha value was .88, above the accepted indicator of a good internal reliability for a scale that is .70 . The final value for the self-efficacy resulted as a mean value of the scores for the nine statements and, for the dataset used in this study, ranged between a minimum value of 1.68 and a maximum value of 4.89 .

\section{Perceived Motivation}

Three semantic-differential questions (boring/interesting; dry/motivational; dull/lively) using a 9point evaluation scale (1-low to 9-high) measured students' perceived motivation in the GIS laboratory (33). The three motivation questions had a consistent internal reliability across all student groups as confirmed by Cronbach's alpha value of .83. Therefore, the final value for the perceived motivation resulted as the average score of the three semantic-differential questions with potential values ranging from " 1 " for low perceived motivation to " 9 " for high perceived motivation.

\section{Perceived Difficulty}

Perceived difficulty was used as a proxy measure for perceived task complexity. It was measured with four semantic-differential questions (easy/hard; simple/complicated; effortless/labor intensive; painless/painful) using a 9-point evaluation scale ranging from "1" for low to "9" for high (33). The four difficulty questions had a consistent internal reliability across all student groups with a Cronbach's alpha value of .81. Therefore, the final value for the perceived difficulty resulted as the average score of the four semantic-differential questions and for the dataset used in this study ranged between a minimum of 1.75 and a maximum of 9.0.

\section{Proposed Path Analysis Model}

The GIS laboratory was implemented as a face-to-face classroom activity with online tutorial support. Previous research findings suggest that self-efficacy potentially has a mediated effect between its determinants, perceived motivation and perceived difficulty, and students' performance outcomes $(24,25)$. 
To test if in this case a mediating effect or only an indirect effect (34) can be observed, the two determinants of self-efficacy, perceived motivation and perceived difficult were regressed on students' performance outcomes, and no significance, $\mathrm{F}(2,114)=1.23, \mathrm{p}=.30$ was found.

Since perceived motivation and perceived difficulty are not significant predictors for students' performance outcomes, we proposed a model that builds on an indirect effect of self-efficacy and its determinants on the students' performance outcomes. Figure 2 shows the associated path analysis conceptual model that describes this indirect effect.

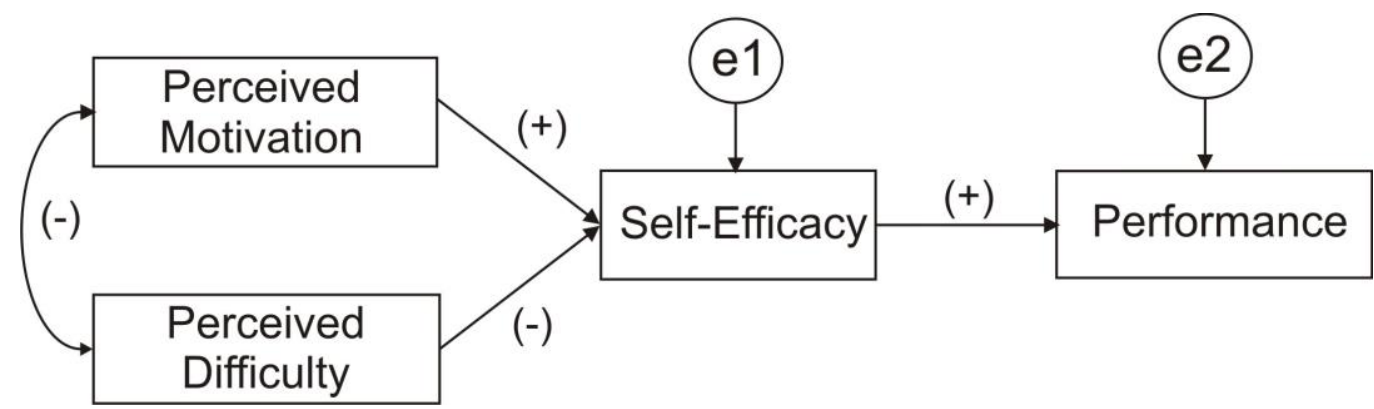

Figure 2. Proposed Conceptual Model for the GIS Laboratory Activity

As suggested by previous research, perceived motivation is predicted to have a positive correlation (+) with self-efficacy, while perceived difficulty is predicted to have a negative correlation (-) with both self-efficacy and perceived motivation. In addition, self-efficacy is predicted to have a positive correlation (+) with performance outcomes. The model also shows the measurement errors, e1 and e2, associated with the two endogenous variables, self-efficacy and respectively performance outcome.

\section{Participants}

Participants in this research were mostly juniors and some seniors enrolled in an introductory Transportation Engineering course. From the 113 students that participated in this study, 24 were enrolled in Fall 2009, 28 in Spring 2010, 34 in Fall 2010 and respectively 27 in Spring 2011. Overall, the self-reported GPA score for the 107 students that provided this information varied from 1.9 to 4.0 with a mean of 3.1. A one-way ANOVA analysis found no significant difference for the GPA scores across the four semesters. To further test the homogeneity of students' characteristics throughout the four semesters an entry survey was administered on the first day of class. Table 2 summarizes the basic statistics for the variables used to analyze group homogeneity.

The expected motivation and difficulty associated with the course were measured with the 9point semantic-differential scales used for the path model variables previously described. Selfreported computer skills (Excel, AutoCAD, PowerPoint) were measured with a 10- point scale (" 1 "- novice to "10" -expert). Finally, for the entry assessment eleven multiple-choices test questions that covered basic algebra, geometry, physics and surveying problems, were administered. The final score was computed as a percentage of the maximum potential score for all test items. 
Table 2. Homogeneity of Students' Characteristics

\begin{tabular}{|c|c|c|c|c|c|c|c|}
\hline & \multicolumn{2}{|l|}{ Variable } & \multicolumn{5}{|c|}{ Basic Statistics } \\
\hline & Entry & 1 & 2 & 3 & 4 & M & SD \\
\hline 1. & Expected motivation (1-9) & - & -.02 & $.20 *$ & -.03 & 5.83 & .95 \\
\hline 2. & Expected difficulty (1-9) & & - & -.13 & .07 & 5.93 & 1.04 \\
\hline 3. & Computer skills $(1-10)$ & & & - & -.06 & 5.84 & 1.12 \\
\hline 4. & Entry assessment $(\%)$ & & & & - & 70.38 & 15.73 \\
\hline
\end{tabular}

Note: $* \mathrm{p}<.05$

A one-way ANOVA analysis for each of the four entry variables above-described indicated that there was no statistically significant difference among the four groups of students included in this study. Therefore, at the entry point the students enrolled in this course from fall semester 2009 to spring semester 2011 were homogeneous and could be combined in one group for the scope of this study.

\section{RESULTS FORM THE PATH MODEL ANALYSIS}

Path analysis, a form of Structural Equation Modeling (SEM), allows to specify a priori, for inferential purposes, the relation between students' performance outcome, academic self-efficacy and two of its major determinants, perceived motivation and perceived task complexity (35). The sample size for this study was within the limits of cases/parameter ratio 28:1, being significantly higher than the minimal value recommended in the literature, 5:1. AMOS (v.18) was the software platform used to test the proposed path model presented in Figure 2.

$\underline{\text { Results from Basic Statistical Analysis }}$

Table 3 presents the basic statistics for each of these measured variables including the endogenous (dependent) and exogenous (independent) variables.

Table 3. Path Model Analysis: Basic Statistics for Path Variables

\begin{tabular}{|c|c|c|c|c|c|c|c|}
\hline & \multicolumn{2}{|l|}{ Variable } & \multicolumn{5}{|c|}{ Basic Statistics } \\
\hline & Exit & 1 & 2 & 3 & 4 & M & SD \\
\hline 1 . & Perceived motivation & - & $-.21 *$ & $.33 * *$ & -.06 & 5.05 & 1.40 \\
\hline 2. & Perceived difficulty & & - & $-.45 * *$ & -.12 & 5.01 & 1.57 \\
\hline 3. & Self-efficacy & & & - & $.18 *$ & 3.63 & .69 \\
\hline 4. & Recall test & & & & - & 64.87 & 19.03 \\
\hline
\end{tabular}

Notes: $* \mathrm{p}<.05$ (2-tailed); $* * \mathrm{p}<.01$ (2-tailed)

The correlation analysis results confirm the two predictions made in the proposed path model. First, perceived motivation shows a statistically significant positive correlation to self-efficacy while perceived difficulty shows a statistically significant negative correlation to self-efficacy. Second, self-efficacy shows a statistically significant positive correlation to the recall test scores. 


\section{The Overall Model}

The minimum discrepancy measured by chi-square was not significant, $\chi^{2}(2)=2.12, p=.35$, which indicates that there is an adequate close fit between the hypothesized model and the perfect fit model. A more sensitive measure linked to this statistics is the ratio of the minimum discrepancy to the degrees of freedom, which for the proposed model was CDMIN/DF $=1.06$ and confirmed the adequacy of model fit as this value is smaller than 2.0 as recommended in the literature (36). Figure 3 summarizes the resulted path coefficients, their statistical significance as well as the variance explained by each of the two target variables, self-efficacy and respectively performance outcome.

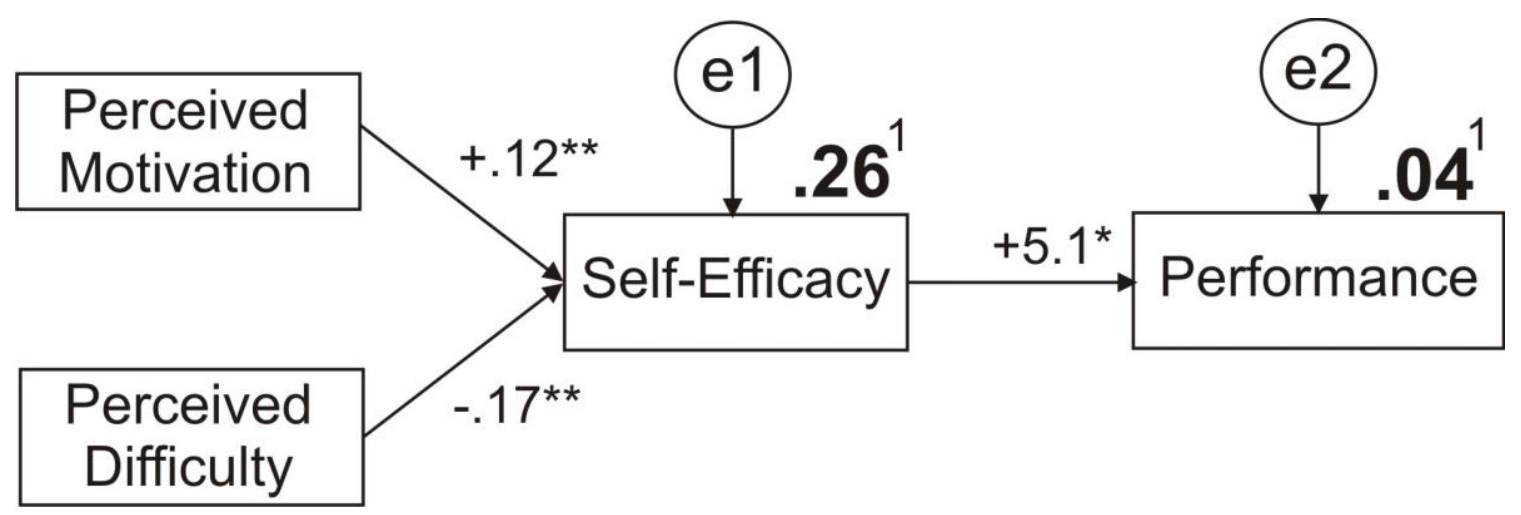

Notes:

Significance of Standardized Path Coefficients $* \mathrm{p}<.05 ; * * \mathrm{p}<.01$;

${ }^{1}$ Squared Multiple Correlations (explained variance);

Figure 3. Path Coefficients for the proposed model of GIS Laboratory

\section{$\underline{\text { Goodness-of-Fit Measures }}$}

All major goodness-of-fit statistics recommended in the literature $(35,36)$ indicated a good fit for the proposed models, as follows:

a) Goodness-of-fit index, GFI = .99, and adjusted-goodness-of-fit, AGFI $=.95$, are equal or higher than .95 ,

b) Comparative fit index, $\mathrm{CFI}=.99$, higher than .95 , the recommended value, and

c) Root mean square error of approximation, RMSEA $=.02$, smaller than .06 , a value recommended by the literature (36).

In addition, Holter critical sample size statistic, Holter $(\mathrm{p}=.05)=322$, is higher than 200 which is indicative of a model that adequately represents the sample data used (35).

\section{THE IMPACT OF THE NATURE OF LABORATORY IMPLEMENTATION}

To test if the nature of the laboratory implementation produced a significant shift in the three predictors of the performance outcome proposed in the path model, a series of one-way ANOVA analyses was carried out. 
The between-groups factor used was the nature of laboratory implementation, with two levels: 1) independent laboratory, for Fall 2009 and Spring 2010, and 2) anchored laboratory, tied to the semester-long design project for the implementation of the laboratory (Fall 2010, Spring 2011). The dependent variables tested against the nature of the laboratory implementation were the perceived difficulty, perceived motivation and respectively self-efficacy.

This analysis revealed a significant effect for the nature of laboratory implementation for: a) selfefficacy, $\mathrm{F}(1,113)=13.93, \mathrm{p}<.001$ and respectively one of its predictors, $\mathrm{b})$ perceived difficulty, $\mathrm{F}(1,113)=33.19, \mathrm{p}<.001$. No statistically significant difference was observed for perceived motivation.

Figure 4 displays sample means, which indicates that self-efficacy (a 1 to 5 scale), significantly increased, while perceived difficulty (a 1 to 9 scale) significantly decreased when the laboratory was anchored in the context of the highway design project.

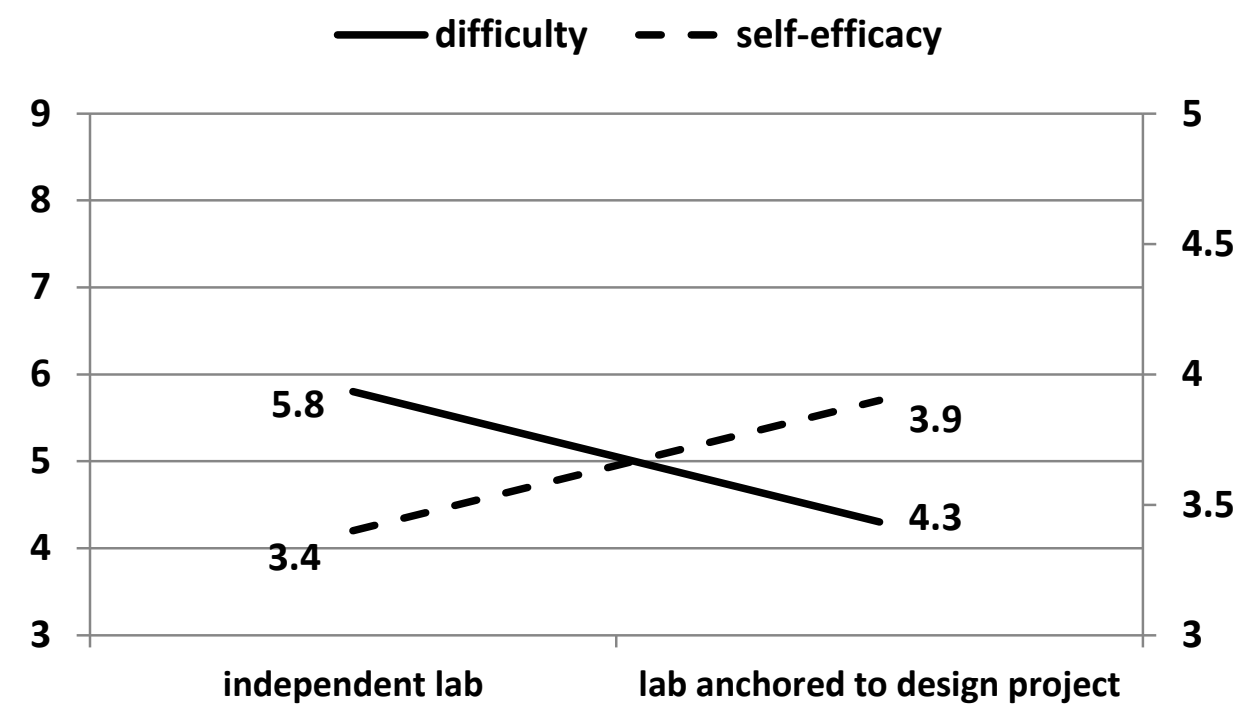

Figure 4. The impact of the nature of laboratory implementation on two of the predictors of student performance outcomes

\section{DISCUSSION AND CONCLUSIONS}

While this study focused on the implementation and refinement of an online learning environment developed for transportation engineering the process, findings and lesson learned described below are valid for any instructional field interested in optimizing the impact of online modules on students' learning.

Very often online learning modules for undergraduate instruction, in our case the GIS module, are developed by teams of faculty and graduate students. That's why they are first tested with groups of graduate students and, at best, also tested with small groups of undergraduate students outside of the actual classroom environment. This approach oversimplifies the learning environment and therefore produces biased views on major factors such as complexity of the task or motivation that impact the learning process. To address this shortcoming we engaged in a 
series of formative implementations of the online environment that allowed us to measure such factors and make changes according to these findings. However, in our case, the tested online modules were not strongly tied to a significant grading measure. Therefore we decided to use self-efficacy as an indicator for students' learning outcomes. Along with the fact that this variable was proved in prior research as being a strong proxy for students' learning outcomes another advantage of using self-efficacy is the fact that it is easy to measure using a selfreporting survey. Therefore, for each cycle of implementation we measured these variables and made changes that reduced the complexity and increased students' self-efficacy. Most of these changes are likely to be valid in other cases of initial implementations of a new online learning module. For example, avoiding the unnecessary complexity of the instructional tasks, providing additional in-class support and integrating the online module with a major task in the course are likely to produce positive changes in students' self-efficacy.

The potential impact of these factors was also supported by the findings from the path analysis model proposed in this study. From the overall model, the path coefficients indicate that both perceived motivation and perceived difficulty are significant predictors for students' academic self-efficacy and explain about $24 \%$ of its variance. As expected, perceived motivation has a positive relation with self-efficacy, while perceived task complexity has a negative relation with self-efficacy. The model then confirmed that the instructional design interventions increased students' trust in their ability to learn the topic introduced in the GIS laboratory. A better alignment of the complexity of the laboratory activity with the level of students' expectations produced the desired outcome, a higher self-efficacy. Higher self-efficacy typically results in higher chances that students will successfully engage in similar future activities. This outcome is of high interest, as the GIS laboratory was set as a distributed learning activity implemented as stand-alone laboratories in several courses throughout the civil engineering curricula $(12,13)$.

Finally we wanted to test if self-efficacy that we used as a proxy for students' performance is in our case linked to the actual performance measures as suggested by previous educational research. We found that academic self-efficacy was a significant, but weak predictor of performance outcome, as it explains only $4 \%$ of its variance. In our study, one potential cause of this weak predictive power can be explained by the nature of the measurement of performance outcome. That is, performance outcome was measured in an unannounced test, one week after the completion of the laboratory activity, and therefore it indicates pure memory recall rather than typical outcome of a well-prepared assessment activity. Another potential cause for this weak relation can be the relative short time of the instructional activity, which did not provide students with enough opportunities for feedback on their performance. Therefore, students did not have enough support to make a strong link between their perception of how well they think they know the topic at hand and the actual results of assessment activities associated with that topic.

Further research is needed to test this model when the assessment strategies used to measure students' performance outcomes builds on opportunities to provide students with feedback on their learning progress. 


\section{ACKNOWLEDGEMENTS}

This research is based upon work supported by the National Science Foundation under Grant No. 0717241. Any opinions, findings, and conclusions or recommendations expressed in this material are those of the authors and do not necessarily reflect the views of the National Science Foundation. The authors also like to acknowledge Aparna, Protyush, and Nitswana for developing the web pages, and Uday for testing and improving the transportation module, and all for help with data collection for the transportation engineering module.

\section{REFERENCES}

1. Kirschner, P.A. \& Paas, F. Web-enhanced higher education: a tower of Babel. Computers in Human Behavior, 17, 2001, pp. 347-353.

2. Demetriadis, S.N., Papadopoulos, P.M., Stamelos, I.G. \& Fischer, F. The effect of scaffolding students' context-generating cognitive activity in technology-enhanced case-based learning. Computers \& Education, 51, 2008, pp. 939-954.

3. Smith, R. M., and Cunningham, P. M. "The independent learners' sourcebook", Chicago: IL, American Library Association, 1987.

4. Zacharia, Z. and Jennings, B. "The Use of Active Learning and Group Competition to Facilitate Training and Technology Transfer for Adult Learners", Transportation Research Board, National Research Council, Washington D.C., TRR Record 1637, 1998, pp. 13-17.

5. Srinivasan, S. and Crooks, S. "Multimedia in a Science Learning Environment." Journal of Educational Multimedia and Hypermedia, 14(2), 2005, pp. 151-167.

6. Graff, M. "Constructing and Maintaining and Effective Hypertext-Based Learning Environment." Education and Training, 48(2/3), 2006, pp. 143-155

7. Jackson, M.J. and Helms, M.M. "Student Perceptions of Hybrid Courses: Measuring and Interpreting Quality." Journal of Education for Business, 84(1), 2008, pp. 7- 12.

8. Mackey, P.T. and Jinwon, H. "Exploring the Relationship between Web Usability and Students' Perceived Learning in Web-Based Multimedia (WBMM) Tutorials." Computers and Education, 50, 2008, pp. 386-409.

9. Sun, P-C., Tsai, R.J., Finger, G., Chen, Y-Y. and Yeh, D. "What Drives a Successful e-Learning? An Empirical Investigation of the Critical Factors Influencing Learner Satisfaction." Computers and Education, 50(4), 2008, pp. 1183-1202.

10. ITE Technical Council Committee 2-32. "Attracting Students to a Professional Career in Transportation Engineering." ITE Journal, 60(1), 1990, pp. $42-48$.

11. Handy, S., Weston. L., Song, J., and Lane, D. "Education of Transportation Planning Professionals". Transportation Research Record, 1812, 2002, pp. 151-160.

12. Luna, R., Hall, R., Hilgers, M., Bham, G., Morris, C., and Morrison, G. "Introduction of GIS into Civil Engineering Curricula.” 2008 ASEE Annual Conference and Exposition, Pittsburg, PA.

13. Luna, R., Hall, R., Hilgers, M., and Ge, L. "A GIS Learning Tool for Civil Engineers", Intl. Journal of Engineering Education, (ISSN:0949-149X), 26(1), 2010, pp. 52-58.

14. Learn Civil GIS, "Transportation." <http://www.learn-civil-gis.org/transportation.aspx> (July 1, 2010).

15. Bham, G., Cernusca, D., Manepalli, U. \& Luna, R. Student-Centered Evaluation of a GIS Laboratory in Transportation Engineering. Paper AC 2010-896. Proceedings of the 2010 ASEE Annual Conference \& Exposition, June 20-23, 2010, Louisville: KY.

16. Brown, J. S., Collins, A. and Duguid, S. "Situated Cognition and the Culture of Learning." Educational Researcher, 18(1), 1989, pp. 32-42.

17. Cognition and Technology Group at Vanderbilt - CTGV “Anchored Instruction and Situated Cognition Revisited.” Educational Technology, 33(3), 1993, pp. 52-70. 
18. Stajkovic, A.D. and Luthans, F. "Self-Efficacy and Work-Related Performance: A Meta-Analysis", Psychological Bulleting, 124(2), 1998, pp. 240-261.

19. Bandura, A. "Self-efficacy: Toward a Unifying Theory of Behavioral Change", Psychological Review, 84(2), 1977, pp. 191-215.

20. Davis, M.A., Curtis, M.B. and Tschetter, J.D. "Evaluating Cognitive Training Outcomes: Validity and Utility of Structural Knowledge Assessment", Journal of Business and Psychology, 18(2), 2003, 191-206.

21. Jonassen, D.H., Beissner, K. and Yacci, M. "Structural Knowledge. Techniques for Representing, Conveying, and Acquiring Structural Knowledge", 1993, Hillsdale, NJ: Lawrence Erlbaum Associates, Inc., Publishers.

22. Multon, K.D., Brown, S.D. and Lent, R.W. "Relation of Self-Efficacy Beliefs to Academic Outcomes: A Meta-Analytic Investigation”, Journal of Counseling Psychology, 38(1), 1991, pp. 30-38.

23. Schunk, D.H. "Self-Efficacy and Education and Instruction", In: J.E. Maddux (Ed.), Self-Efficacy, Adaptation, and Adjustment. Theory, Research, and Application, (pp. 281- 303), New York, NY: Plenum Press, 1995.

24. Bates, R. and Khasawneh, S. "Self-Efficacy and College Students' Perceptions and Use of Online Learning Systems", Computers in Human Behavior, 23, 2007, pp. 175-191.

25. Chyung, S.Y., Moll, A.J. and Berg, S.A. "The Role of Intrinsic Goal Orientation, Self-Efficacy, and E-Learning Practice in Engineering Education, The Journal of Effective Teaching, 10(1), 2010, pp. 22-37.

26. Crippen, K.J., Biesinger, K.D., Muis, K.R. and Orgill, M. "The Role of Goal Orientation and SelfEfficacy in Learning from Web-Based Worked Examples", Journal of Interactive Learning Research, 20(4), 2009, pp. 385-403.

27. Gist, M.E. and Mitchell, T.R. "Self-Efficacy: a Theoretical Analysis of its Determinants and Maleability", The Academy of Management Review, 17(2), 1992, pp.183-211.

28. Wood, R.E. "Task Complexity: Definition of the Construct", Organizational Behavior and Human Decision Processes, 37, 1986, pp. 60-82.

29. Lodewyk, K.R., Winne, P.H. and Jamieson-Noel, D.L. "Implications of Task Structure on SelfRegulated Learning and Achievement", Educational Psychology, 29(1), 2009, pp. 1-25.

30. Christiaansen, R. E. (1980). "Prose memory: Forgetting rates for memory codes." J. Exp. Psychol., 6(5), 611-619.

31. Goshen-Gottstein, Y., and Kempinsky, H. "Probing memory with conceptual cues at multiple retention intervals: A comparison of forgetting rates on implicit and explicit tests." Psychonomic Bulletin and Review, 8(1), 2001, 139-146.

32. Pintrich P. R., and De Groot, E.V. "Motivational and Self-Regulated Learning Components of Classroom Academic Performance.” Journal of Educational Psychology, 82(1), 1990, pp. 33-40.

33. Bham, G. H., Cernusca, D., Luna, R. and Manepalli, U.R. A Longitudinal Evaluation of a GIS Laboratory in a Transportation Engineering Course, Journal of Professional Issues in Engineering Education \& Practice, 137(4), 2011, pp. 258-266.

34. Holmbeck, G.N. (1997). Toward Terminological, Conceptual, and Statistical Clarity in the Study of Mediators and Moderators: Examples from the Child-Clinical and Pediatric Psychology Literatures. Journal of Consulting and Clinical Psychology, 65(4), 1997, pp. 599-610.

35. Byrne, B.M. "Structural Equation Modeling with AMOS. Basic Concepts, Applications, and Programming". Mahwah, NJ: Lawrence Erlbaum Associates, Publishers, 2001.

36. Schreiber, J.B., Stage, F.K., King, J., Nora, A. and Barlow E.A. "Reporting Structural Equation Modeling and Confirmatory Factor Analysis Results: A Review", The Journal of Educational Research, 99 (6), 2006, pp. 323-337. 